\title{
MicroRNA-145-5p aggravates cell apoptosis and oxidative stress in tongue squamous cell carcinoma
}

\author{
ZENGXI XIN $^{1 *}$, ZHOU TONG $^{2 *}$, JINGYU TAN $^{3}$ and CHANGFU LIU ${ }^{2}$ \\ Departments of ${ }^{1}$ Prosthodontics and ${ }^{2}$ Oral and Maxillofacial Surgery, The Second Affiliated \\ Hospital of Jinzhou Medical University; ${ }^{3}$ Department of Stomatology, The First Affiliated \\ Hospital of Jinzhou Medical University, Jinzhou, Liaoning 121000, P.R. China
}

Received December 18, 2019; Accepted December 8, 2020

DOI: $10.3892 /$ etm.2021.9804

\begin{abstract}
MicroRNA-145-5p (miR-145-5p) is expressed in a variety of tumors, but the mechanism underlying miR-145-5p in tongue squamous cell carcinoma (TSCC) is not fully understood. Therefore, the present study investigated the role of miR-145-5p in TSCC. miR-145-5p expression levels in TSCC tissues were analyzed via reverse transcription-quantitative PCR. miR-145-5p mimics and inhibitors were transfected into SCC9 and Cal27 cells. The stability and invasion of SCC9 and Cal27 cells were analyzed by performing Transwell assays, while PI and Annexin V were used to detect cell apoptosis. Oxidative stress levels of superoxide dismutase, malondialdehyde and glutathione peroxidase were measured via ELISA. PI3K/AKT signaling pathway-associated protein expression levels were evaluated using western blotting. miR-145-5p was consistently downregulated in TSCC tissues compared with healthy tissues. miR-145-5p overexpression decreased cell stability and invasion, but promoted cell apoptosis and oxidative stress. In addition, PI3K, AKT and phosphorylated-AKT expression levels were significantly diminished. The results indicated that miR-145-5p overexpression inhibited SCC9 and Cal27 cell stability and invasion, promoted SCC9 and Cal27 cell apoptosis and oxidative stress, and inhibited the PI3K/AKT signaling pathway. The results of the present study suggested that miR-145 may serve as a molecular marker of TSCC.
\end{abstract}

Correspondence to: Dr Changfu Liu, Department of Oral and Maxillofacial Surgery, The Second Affiliated Hospital of Jinzhou Medical University, Section 2, 49 Shanghai Road, Guta, Jinzhou, Liaoning 121000, P.R. China

E-mail: liuchangfu121@sina.cn

\section{* Contributed equally}

Abbreviations: TSCC, tongue squamous cell carcinoma; miRNA, microRNA; SOD, superoxide dismutase, GSH-Px, glutathione peroxidase, MDA, malondialdehyde; NSCLC, non-small cell lung cancer

Key words: miRNA-145-5p, TSCC, apoptosis, oxidative stress, $\mathrm{PI} 3 \mathrm{~K} / \mathrm{AKT}$ signaling pathway

\section{Introduction}

Tongue cancer is one of the most common malignant tumor types that occurs in the oral and maxillofacial region (1). Of the pathological types of tongue cancer, $>80 \%$ are tongue squamous cell carcinoma (TSCC) (2). The majority of lesions occur at the edge of one third of the tongue, but the second most common area that lesions occur is the root, dorsum and tip of the tongue (3). TSCC is prone to metastasis via the lymph and blood circulation (4). Patients with low differentiation are prone to recurrence after operation (3), and radiotherapy and chemotherapy treatment strategies are not effective, resulting in a poor prognosis. Therefore, identifying an effective treatment strategy is the focus of clinical research on TSCC.

MicroRNAs (miRNAs/miRs) are a group of non-coding single-stranded RNA molecules that are involved in the regulation of post-transcriptional gene expression in plants and animals (5). Previous studies have reported that a single miRNA can affect the expression of 1,000s of genes and that several miRNAs can affect the expression of a single gene at the same time (6-8). miRNAs are associated with the expression of one third of human genes. In the study of oncogenesis, it has been revealed that miRNAs can interfere with the synthesis of proteins by affecting the initiation of translation, thereby further affecting the biological effects of oncogenes and tumor suppressor genes (9).

miR-145, located on human chromosome 5q32, acts as a tumor suppressor in a variety of tumors, including prostate, bladder, colon, ovarian and esophageal cancer, and is expressed at lower levels in tumor tissues compared with normal tissues (10-14). However, the role of miR-145 in TSCC and its related mechanisms are yet to be elucidated. Thus, the present study investigated the role and mechanism underlying miR-145 in SCC9 and Cal27 cell apoptosis and oxidative stress, with the aim of providing a theoretical foundation for the identification of novel molecular markers and treatments.

\section{Materials and methods}

Patients and tissue samples. A total of 43 tumor tissue samples from patients with TSCC (26 male patients and 17 female patients; age range, 32-74 years; median age, 52 years) who were admitted to the Department of Oral 
and Maxillofacial Surgery, the Second Affiliated Hospital of Jinzhou Medical University were obtained between January 2017 and December 2018. None of the patients had received chemotherapy or radiotherapy. The inclusion criteria were as follows: i) Diagnosed with TSCC by pathology; and ii) had not received radiation therapy or chemotherapy prior to the biopsy. Patients with $\geq 1$ of the following conditions were excluded from the present study: i) Infectious disease; ii) acute cardiovascular and cerebrovascular diseases; iii) rheumatic disease; iv) diabetes; and v) other tumors. In addition, the paracancerous tissues (adjacent non-tumorous tissues, normal tongue tissues) of 43 patients with TSCC were obtained from The Second Affiliated Hospital of Jinzhou Medical University as the control group.

The present study was approved by the Ethics Committees of Jinzhou Medical University on October 26, 2016 (approval no. JZH2016052). Written informed consent was obtained from all patients included in the present study.

Cell culture. TSCC Cal27 and SCC9 cell lines were purchased from The Cell Bank of Type Culture Collection of Chinese Academy of Sciences. Cal27 cells were cultured in DMEM (Gibco; Thermo Fisher Scientific, Inc.) containing 10\% FBS (Gibco; Thermo Fisher Scientific, Inc.) in a $5 \% \mathrm{CO}_{2}$ incubator at $37^{\circ} \mathrm{C}$ with saturated humidity. SCC 9 cells were incubated in RPMI-1640 medium (Gibco; Thermo Fisher Scientific, Inc.) containing $10 \% \mathrm{FBS}$ in a $5 \% \mathrm{CO}_{2}$ incubator at $37^{\circ} \mathrm{C}$.

Transfection. miR-145-5p mimics (cat. no. miR30000157-1-2) and inhibitors (cat. no. miR20000437-1-2) were synthesized along with a corresponding negative control (NC; Lentiviral vector without gene sequence) by Shanghai GenePharma Co., Ltd. Plasmid production and purification were also performed by Shanghai GenePharma Co., Ltd, following the manufacturer's protocols. miR-145-5p mimic and inhibitor sequences were cloned into the lentivirus without green fluorescence (GeneChem, Inc.). Subsequently, $6 \mu \mathrm{g} / \mathrm{ml}$ polybrene (GeneChem, Inc.) and an appropriate amount of lentivirus were added and incubated at $37^{\circ} \mathrm{C}$ for $24 \mathrm{~h}$. Cells transfected with lentivirus were screened with puromycin to increase transfection efficiency. Transfection efficiency was assessed by performing reverse transcription-quantitative PCR (RT-qPCR).

$R T-q P C R$. Total RNA was extracted from the tissues or cells using TRIzol ${ }^{\circledR}$ reagent (Invitrogen; Thermo Fisher Scientific, Inc.) according to manufacturer's protocol. Total RNA was reverse transcribed into cDNA using the Prime Script ${ }^{\mathrm{TM}}$ RT Master Mixture (Takara Biotechnology Co., Ltd.) according to the manufacturer's protocol. The following thermocycling conditions were used for cDNA: $37^{\circ} \mathrm{C}$ for $15 \mathrm{~min}$ and $85^{\circ} \mathrm{C}$ for $15 \mathrm{sec}$. Subsequently, qPCR was performed using the SYBR Prime Script miRNA RT-PCR kit (Takara Biotechnology Co., Ltd.). The following thermocycling conditions were used for qPCR: Pre-denaturation at $95^{\circ} \mathrm{C}$ for $1 \mathrm{~min}$, followed by 40 cycles of denaturation at $95^{\circ} \mathrm{C}$ for $15 \mathrm{sec}$, annealing at $60^{\circ} \mathrm{C}$ for $40 \mathrm{sec}$ and extension at $72^{\circ} \mathrm{C}$ for $15 \mathrm{sec}$. The expression level of miR-145-5p was calculated using the $2^{-\Delta \Delta C q}(15)$ method and normalized to the internal reference gene U6. The primers used were as follows: miR-145-5p forward, 5'-ACAC
TCCAGCTGGGGTCCAGTTTTCCCAGGA-3' and reverse, 5'-ACACTCCAGCTGGGGTCCAGTTTTCCCAGGA-3'; U6 forward, 5'-CGCTTCGGCACATATACTA-3' and reverse, 5'-CGCTTCACGAATTTGCGTGTCA-3'.

MTT assay. Cells $\left(8 \times 10^{4}\right.$ cells/well) in logarithmic growth were seeded into a 96-well culture plate. Subsequently, $20 \mu 1$ MTT solution $(5 \mathrm{mg} / \mathrm{ml})$ was added to each well and incubated at $37^{\circ} \mathrm{C}$ for $4-6 \mathrm{~h}$. After the supernatant was removed, $150 \mu \mathrm{l}$ DMSO was added and the 96-well culture plate was gently agitated for $10 \mathrm{~min}$ to dissolve the formazan crystals. The optical density (OD) of each well was measured at a wavelength of $570 \mathrm{~nm}$ using a plate reader. The rate of proliferation (\%) was calculated as follows: (OD sample $\left.-\mathrm{OD}_{\text {sample blank }}\right) /(\mathrm{OD}$ control - OD control blank $) \times 100$.

Transwell assay. SCC9 and Cal27 cells were re-suspended in medium without serum to a concentration of $1 \times 10^{5}$ cells/ $\mathrm{ml}$. Subsequently, cells (200 $\mu \mathrm{l})$ were seeded into the upper chamber of Matrigel ${ }^{\circledR}$-coated (Sigma-Aldrich; Merck KGaA) Transwell inserts (8- $\mu \mathrm{m}$ pore; Sigma-Aldrich; Merck KGaA). RPMI-1640 or DMEM containing 10\% FBS was plated into the lower chamber. Following incubation at $37^{\circ} \mathrm{C}$ for $48 \mathrm{~h}$, cells on the upper surface of the Transwell membrane were removed using a cotton swab. Subsequently, cells were fixed using $4 \%$ paraformaldehyde solution for $20 \mathrm{~min}$ at room temperature, stained with $0.1 \%$ trypan blue for $15 \mathrm{~min}$ at room temperature and observed using a light microscope (magnification, $\mathrm{x} 100)$.

Apoptosis staining. SCC9 and Cal27 cells were collected, washed and then resuspended. Cells were incubated with $5 \mu \mathrm{l}$ Annexin V (cat. no. 556547; BD Pharmingen; BS Biosciences) and $5 \mu 1 \mathrm{PI}$ (cat. no. 556547; BD Pharmingen; BS Biosciences) at room temperature for $20 \mathrm{~min}$ in the dark. Subsequently, cells were washed with PBS and re-suspended in $300 \mathrm{ml}$ PBS. Cell apoptosis was analyzed via Calibur flow cytometer (BD Biosciences) and quantified using FlowJo software (v. 10.1.1; FlowJo LLC).

ELISA. The cell supernatants of SCC9 and Cal27 cells were collected. Levels of malondialdehyde (MDA; cat. no. CEA597Ge; Cloud Clone Corp.), superoxide dismutase (SOD; cat. no. SES134Hu; Cloud Clone Corp.) and glutathione peroxidase (GSH-Px; cat. no. CEA294Ge; Cloud Clone Corp.) were measured using ELISA kits according to the manufacturer's protocols. The OD of each sample was measured at a wavelength of $450 \mathrm{~nm}$ using a microplate reader. A standard curve was generated by plotting OD value vs. standard concentration. The curve equation and $\mathrm{r}$ value were calculated and used to determine concentrations of each sample.

Western blotting. Total protein was extracted from the cells using RIPA lysis buffer (Thermo Fisher Scientific, Inc.). Total protein was quantified using a bicinchoninic acid protein assay kit. Proteins (50 $\mu \mathrm{g} /$ lane) were separated via 10\% SDS-PAGE and transferred onto PVDF membranes. Subsequently, the membranes were incubated at $4^{\circ} \mathrm{C}$ overnight with the following primary antibodies: Anti-PI3K (1:1,000; ab127617; Abcam), anti-AKT (1:1,000; ab179463; Abcam), anti-phosphorylated 
Table I. Characteristic features of study subjects.

\begin{tabular}{|c|c|c|}
\hline Characteristics & $\begin{array}{c}\text { Patients } \\
\text { with TSCC }\end{array}$ & Controls \\
\hline \multicolumn{3}{|l|}{ Age, years } \\
\hline Range & $32-74$ & $33-71$ \\
\hline Mean \pm SD & $52 \pm 8.58$ & $54 \pm 10.21$ \\
\hline Smoking & 23 & 23 \\
\hline Non-smoking & 20 & 20 \\
\hline Drinking & 17 & 23 \\
\hline Non-drinking & 26 & 20 \\
\hline Tumor location & & - \\
\hline Tongue margin & 29 & \\
\hline Tongue root & 8 & \\
\hline Ventral of tongue & 6 & \\
\hline Tumor size & & - \\
\hline $\mathrm{T} 1$ & 4 & \\
\hline $\mathrm{T} 2$ & 23 & \\
\hline $\mathrm{T} 3$ & 11 & \\
\hline $\mathrm{T} 4$ & 5 & \\
\hline Lymph node involvement & & - \\
\hline N0 & 25 & \\
\hline $\mathrm{N}+$ & 18 & \\
\hline Pathological classification & & - \\
\hline Squamous cell carcinoma & 43 & \\
\hline Histological classification & & - \\
\hline Well differentiated & 11 & \\
\hline Moderately differentiated & 27 & \\
\hline Poorly differentiated & 5 & \\
\hline Clinical stage & & - \\
\hline I & 4 & \\
\hline II & 12 & \\
\hline III & 20 & \\
\hline IV & 7 & \\
\hline
\end{tabular}

Data are presented as $\mathrm{n}$, range or mean $\pm \mathrm{SD}$.

(p)-AKT (1:800; ab131443; Abcam) and anti-GAPDH (1:2,000; ab181602; Abcam) antibodies. After washing with PBS three times, the membranes were incubated with a secondary polyclonal peroxidase-labeled antibody (1:4,000; ab7090, Abcam) for $2 \mathrm{~h}$. Protein bands were visualized using enhanced chemiluminescence reagent (Thermo Fisher Scientific, Inc.). Protein expression levels were semi-quantified using ImageJ software (v2.1.4.7; National Institutes of Health) with GAPDH as the loading control.

Statistical analysis. All experiments were performed 2-3 times. Data are presented as the mean \pm SD. Statistical analyses were performed using GraphPad Prism software (version 6.0; GraphPad Software, Inc.). Comparisons between two groups were analyzed using the unpaired two-tailed Student's t-test. Comparisons between multiple groups were analyzed using one-way ANOVA or Kruskal-Wallis test followed by Dunn's

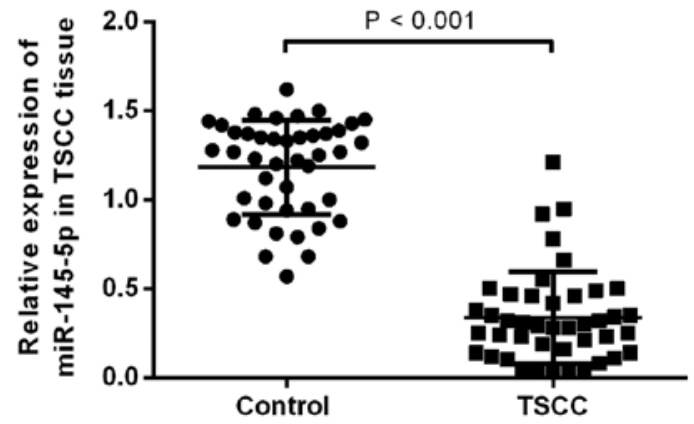

Figure 1. miR-145-5p is downregulated in TSCC tissues. The expression of miR-145-5p in TSCC tissues was detected via reverse transcription-quantitative PCR. Compared with the control group, miR-145-5p expression levels were decreased. miR, microRNA; TSCC, tongue squamous cell carcinoma.

post hoc test. $\mathrm{P}<0.05$ was considered to indicate a statistically significant difference.

\section{Results}

Clinical characteristics of patients with TSCC. The clinical characteristics of the patients with TSCC are presented in Table I. According to the TNM classification for TSCC (The American Joint Committee on Cancer and Union for International Cancer Control 2010; 7th edition) (16), patients were divided into four stages: i) stage I $(n=4)$; ii) stage II $(\mathrm{n}=12)$; iii) stage III $(\mathrm{n}=20)$; and iv) stage IV $(\mathrm{n}=7)$.

miR-145-5p is downregulated in TSCC tissues. To determine the level of miR-145-5p in tissues of patients with TSCC, miR145-5p expression was detected by performing RT-qPCR. The results indicated that the expression level of miR-145-5p in patients with TSCC was significantly decreased compared with the control group $(\mathrm{P}<0.05$; Fig. 1).

miR-145-5p overexpression attenuates SCC 9 and Cal27 cell proliferation. To determine the function of miR-145-5p, SCC9 and Cal27 cell lines were used. miR-145-5p expression levels were detected via RT-qPCR following transfection with $\mathrm{NC}$, miR-145-5p mimics and miR-145-5p inhibitors. The results indicated that miR-145 expression was significantly increased following transfection with miR-145-5p mimic compared with the NC group in both cell lines ( $\mathrm{P}<0.05$; Fig. $2 \mathrm{~A}$ and $\mathrm{B})$. Moreover, miR-145 expression was significantly decreased following transfection with miR-145-5p inhibitor compared with the $\mathrm{NC}$ group $(\mathrm{P}<0.05$; Fig. $2 \mathrm{~A}$ and $\mathrm{B})$. Cell proliferation following transfection was also assessed. The results demonstrated that cell proliferation was significantly decreased following transfection with miR-145-5p mimics compared with the NC group $(\mathrm{P}<0.05$; Fig. $2 \mathrm{C})$. These results suggested that miR-145-5p overexpression suppressed SCC9 and Cal27 cell proliferation. Moreover, inhibiting the expression of miRNA-145-5p did not inhibit cell proliferation.

miR-145-5p overexpression mitigates SCC9 and Cal27 cell invasion. Tumor cells have the ability to metastasize and invade (5); therefore, a Transwell assay was conducted to detect SCC9 and Cal27 cell invasion. The results indicated 


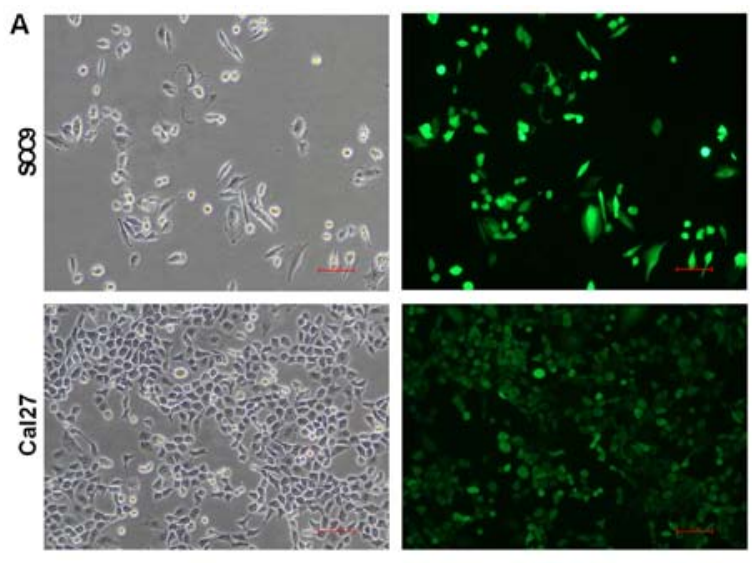

B
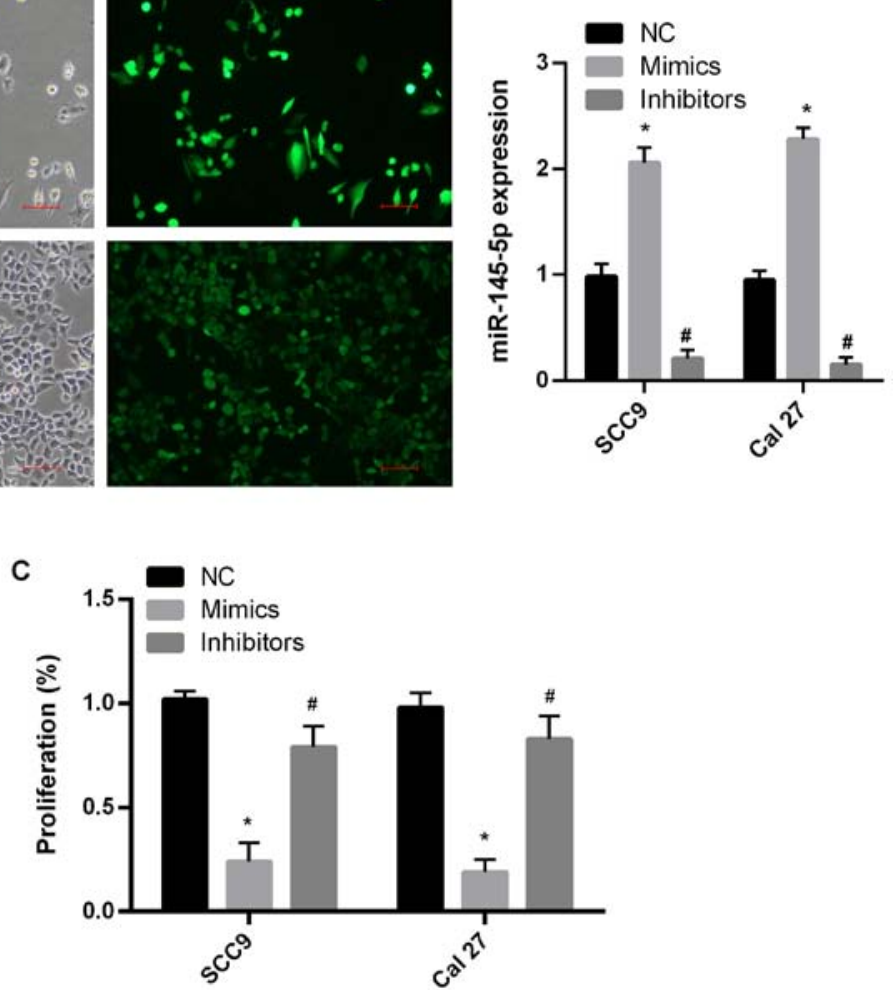

Figure 2. miR-145-5p overexpression suppresses SCC9 and Cal27 cell proliferation. (A) miR-145-5p NC, mimic and inhibitor sequences were transfected into SCC9 and Cal27 cells. magnification, x400. (B) The transfection efficiency was detected by performing reverse transcription-quantitative PCR. (C) An MTT assay was used to detect SCC9 and Cal27 cell proliferation. All experiments were performed in triplicate. ${ }^{*} \mathrm{P}<0.05$ vs. NC; ${ }^{~} \mathrm{P}<0.05$ vs. mimic. miR, microRNA; $\mathrm{NC}$, negative control.

that SCC9 and Cal27 cell invasion was significantly decreased following transfection with miR-145-5p mimics compared with the NC group $(\mathrm{P}<0.05$; Fig. $3 \mathrm{~A}$ and $\mathrm{B})$. Furthermore, the results suggested that miR-145-5p knockdown promoted SCC9 and Cal27 cell invasion.

miR-145-5p overexpression aggravates SCC9 and Cal27 cell apoptosis. PI and Annexin V staining was used to assess early SCC9 and Cal27 cell apoptosis. It was found that early SCC9 and Cal27 cell apoptosis was significantly increased following miR-145-5p overexpression compared with the NC group ( $\mathrm{P}<0.05$; Fig. 4A and B). Following miR-145-5p knockdown, early SCC9 and Cal27 cell apoptosis was significantly diminished compared with the $\mathrm{NC}$ group $(\mathrm{P}<0.05)$. The results indicated that miR-145-5p overexpression aggravated SCC9 and $\mathrm{Ca} 27$ cell apoptosis.

miR-145-5p overexpression promotes SCC9 and Cal27 cell oxidative stress. The supernatants of SCC9 and Cal27 cells were utilized to detect the levels of SOD, MDA and GSH-Px. As presented in Fig. 5A and C, SOD and GSH-Px levels were significantly decreased after miR-145-5p overexpression compared with the NC group $(\mathrm{P}<0.05)$. By contrast, MDA levels were significantly increased after miR-145-5p overexpression compared with the NC group $(\mathrm{P}<0.05$; Fig. 5B). The results suggested that miR-145-5p overexpression promoted SCC9 and Cal27 cell oxidative stress. Inhibition of mirna145-5p expression did not result in inhibition oxidative stress.
miR-145-5p regulates the PI3K/AKT signaling pathway. In order to further investigate the mechanism underlying miR-145-5p, western blotting was performed to detect PI3K signaling pathway-associated protein expression levels. The results indicated that the expression levels of PI3K, AKT and p-AKT were significantly decreased after miR-145-5p overexpression compared with the NC group $(\mathrm{P}<0.05$; Fig. $6 \mathrm{~A}-\mathrm{E})$. After inhibiting the expression of miR-145-5p, the expression levels of PI3K, Akt and p-Akt were significantly increased. Compared with NC group, there was no significant difference. Thus, it was suggested that miR-145-5p regulated the PI3K/ AKT signaling pathway.

\section{Discussion}

miRNA is a highly conserved endogenous non-coding RNA that consists of 18-25 nucleotides (5). Since the discovery of the first miRNA in 1993, an increasing number of studies have demonstrated that miRNA serves an important role in the growth, differentiation and proliferation of organisms $(17,18)$. miR-145-5p is downregulated in a number of different types of cancer, including cervical (19), colorectal (20) and non-small cell lung cancer (NSCLC) (21), as well as in esophageal squamous cell carcinoma. miR-145-5p functions as a tumor suppressor in carcinogenesis $(13,22-27)$, which may be associated with the fragile site of epigenetic alteration caused by the deletion of the gene encoding miR-145 in cancer cells (28). miR-145-5p downregulation in normal 

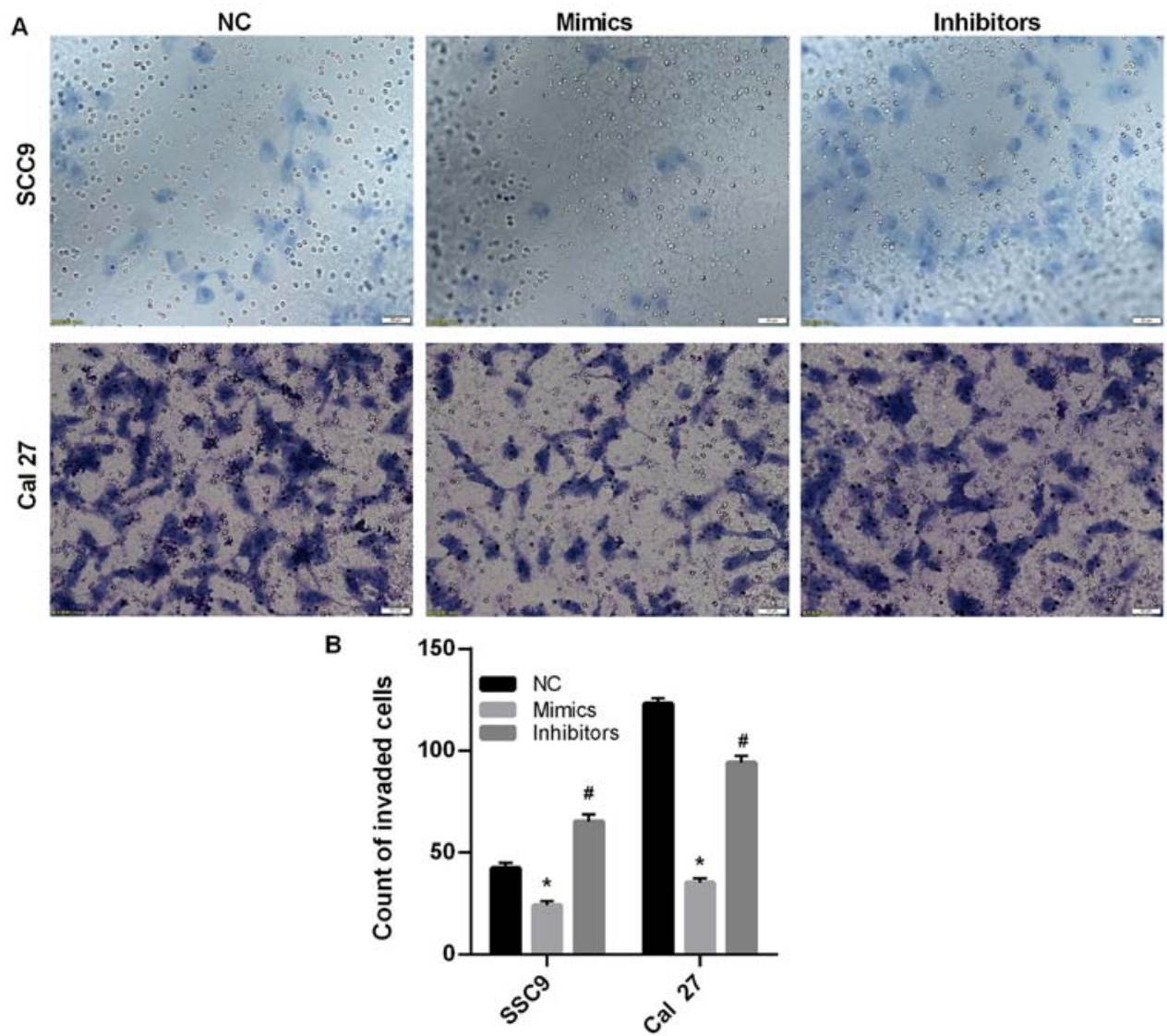

Figure 3. miR-145-5p overexpression mitigates SCC9 and Cal27 cell invasion. Cell invasion was detected by performing (A) a Transwell assay (magnification, x100). miR, microRNA, and (B) the results were quantified. "P<0.05 vs. NC; "P<0.05 vs. mimic. miR, microRNA; NC, negative control.

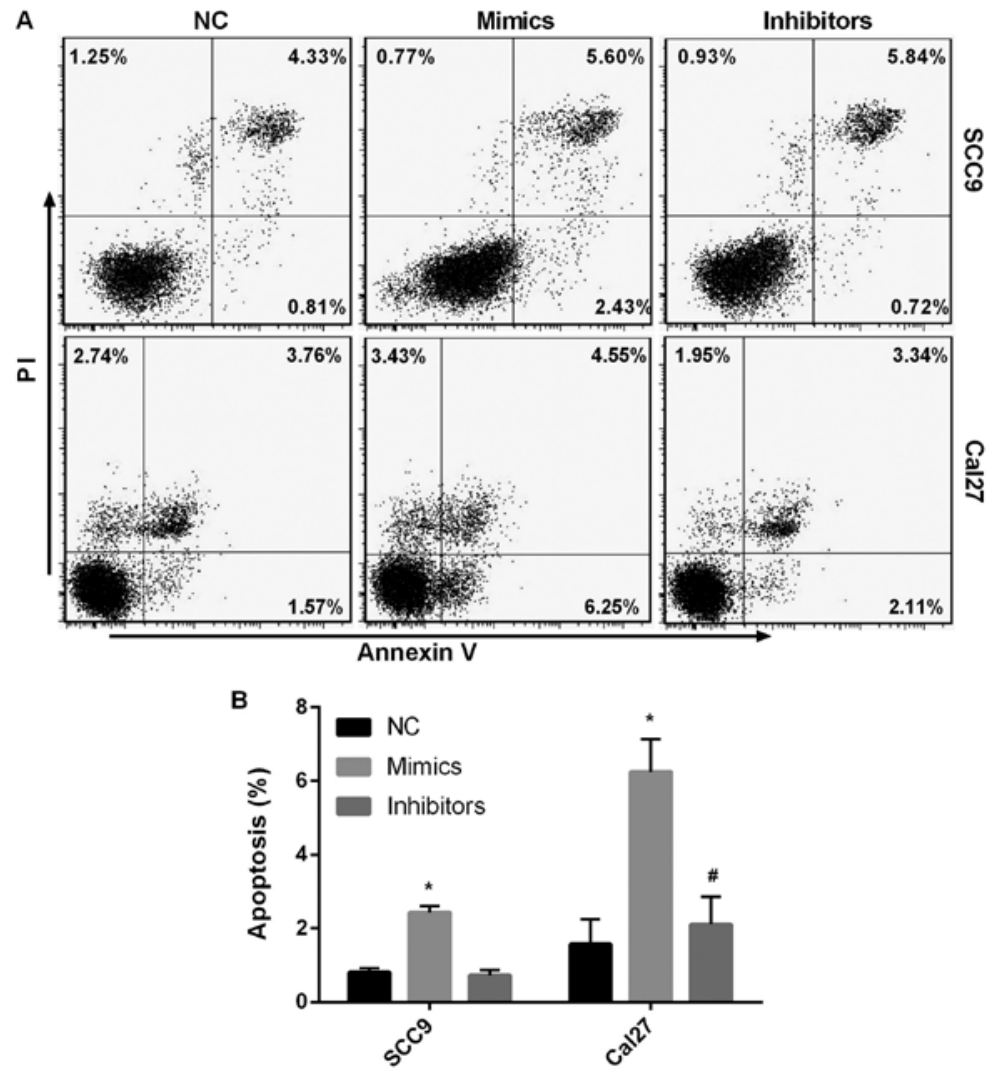

Figure 4. miR-145-5p aggravates SCC9 and Cal27 cell apoptosis. PI and Annexin V staining was utilized to detect SCC9 and Cal27 cell apoptosis via flow cytometry. All experiments were performed in triplicate. miR, microRNA. (A) Scatter diagram of apoptosis. (B) Histogram of apoptosis results. ${ }^{*} \mathrm{P}<0.05$ vs. NC; ${ }^{\mathrm{P}}<0.05$ vs. mimic. miR, microRNA; NC, negative control. 

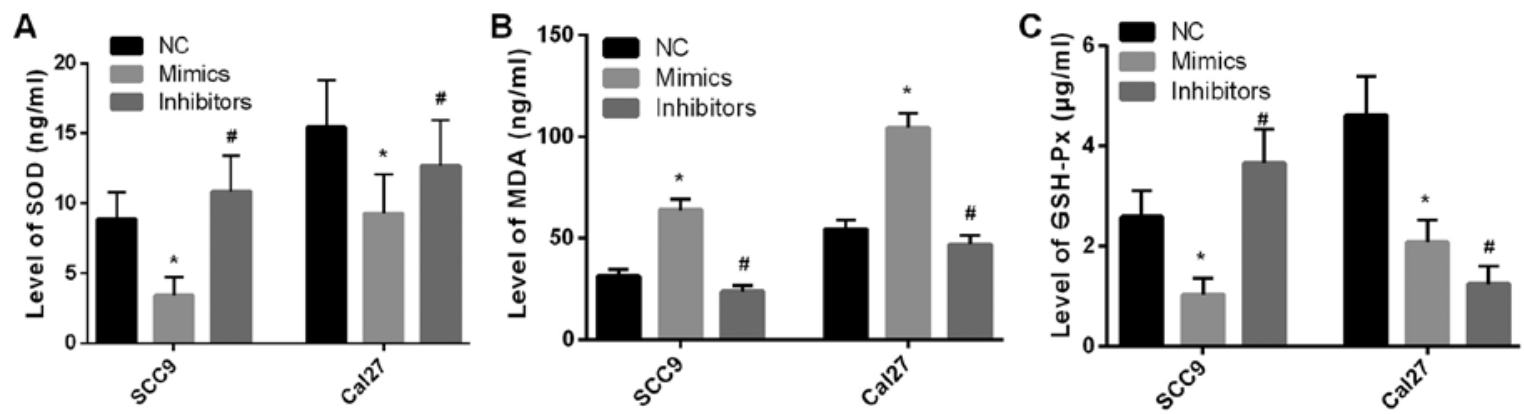

Figure 5. miR-145-5p overexpression promotes SCC9 and Cal27 cell oxidative stress. (A) SOD, (B) MDA and (C) GSH-Px levels were detected by performing ELISAs. "P<0.05 vs. NC; ${ }^{\#} \mathrm{P}<0.05$ vs. mimic. miR, microRNA; SOD, superoxide dismutase; MDA, malondialdehyde; GSH-Px, glutathione peroxidase; NC, negative control.

A

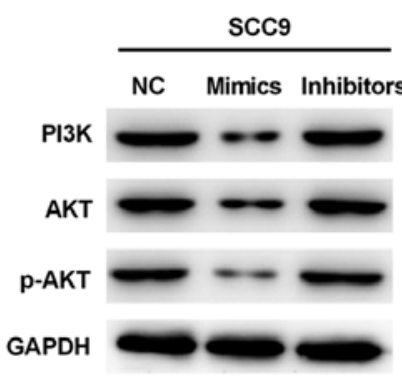

Cal27

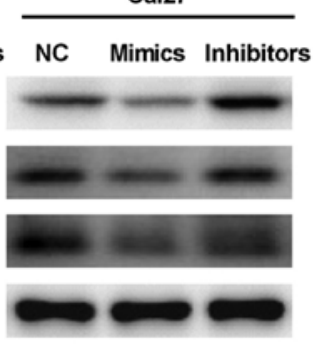

B

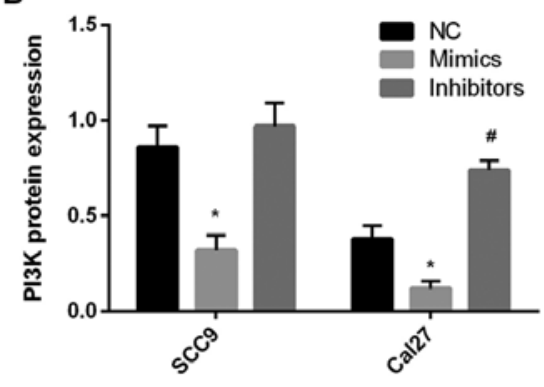

C

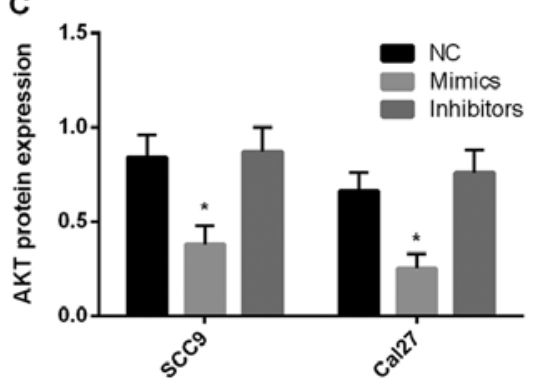

D

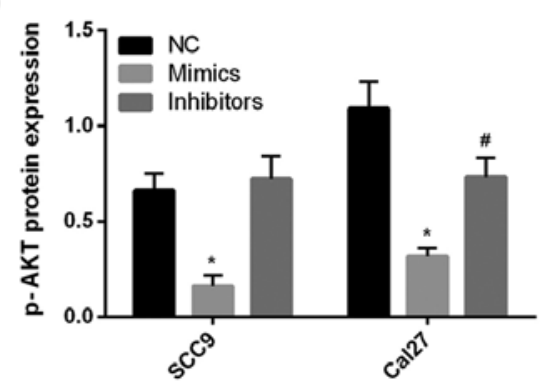

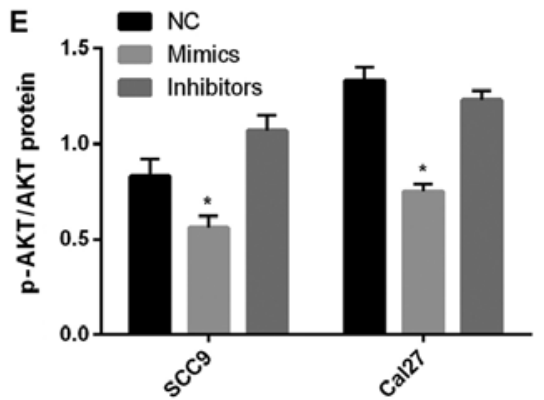

Figure 6. miR-145-5p regulates the PI3K/AKT signaling pathway. (A) Western blotting was used to detect the protein expression levels of the PI3K signing pathway-associated proteins (B) PI3K, (C) AKT and (D) p-AKT were determined by performing western blotting. (E) Ratio of total AKT and p-AKT was calculated. All experiments (technical repeats) were performed in triplicate. " $\mathrm{P}<0.05$ vs. NC; ${ }^{~} \mathrm{P}<0.05$ vs. mimic. miR, microRNA; $\mathrm{p}-$, phosphorylated; NC, negative control.

tissue cells results in the lack of protection and monitoring from miR-145-5p, leading to altered cell functions, including proliferation, apoptosis and migration, and the induction of carcinogenesis. Jin et al (29) reported that miR-145-5p directly targeted the 3'-untranslated region of Toll-like receptor 4, inhibiting the occurrence of malignant melanoma and metastasis. Furthermore, Liu et al (21) reported that miR-145-5p knockdown upregulated $\mathrm{N}$-cadherin, vimentin and E-cadherin protein expression levels and increased epithelial-mesenchymal transition activity, which led to the progression of NSCLC. Kliese et al (30) also revealed that miR-145 overexpression in meningioma cells resulted in decreased proliferation, increased sensitivity to apoptosis and reduced orthotopic tumor growth in nude mice. miR-145 serves an important role in the initiation, proliferation, apoptosis and tumorigenesis of cancer cells (19).

In the present study, the expression of miR-145-5p was decreased in TSCC tissues compared with normal tissues, and miR-145-5p overexpression in SCC9 and Cal27 cells inhibited cell stability and invasion, as well as promoted cell apoptosis. Furthermore, miR-145-5p overexpression in SCC9 and Cal27 cells inhibited the levels of SOD and GSH-Px, and promoted the level of MDA. It was also found that miR145-5p overexpression promoted oxidative stress in these TSCC cells. However, the level of GSH-Px was decreased in miR-145-5p inhibitors group with TSCC Cal27 cells, and it was suggested that some components of the inhibitors interfere with the level of GSH-Px. The present results also demonstrated that miR-145-5p overexpression promoted cell apoptosis and oxidative stress by suppressing the PI3K/AKT signaling pathway.

The PI3K/AKT signaling pathway is an important signal transduction pathway of cell metabolism and antiapoptotic mechanisms, which is closely associated with the occurrence and development of malignant tumors (31). PI3K is a phosphatidylinositol kinase that phosphorylates the third hydroxyl group 
of the inositol ring. Its activation is affected by the cytokineinduced activation of Ras molecule, and the activation signal is transmitted to phosphatidylinositol-3 dependent kinase and then to AKT (32). Zhu et al (33) reported that curcumin inhibited the PI3K/AKT/mTOR signaling pathway by upregulating the expression of miR-145 and attenuated the development of laryngeal squamous cell carcinoma. Moreover, Liu et al (34) revealed that miR-145-5p suppressed VMM917 and CHL-1 cell proliferation, invasion and migration, and induce apoptosis by inhibiting the mitogen activated protein kinase and PI3K/AKT signaling pathways. Li et al (35) also indicated that miR-145 knockdown in NSCLC A549 cells increased cell proliferation, but reduced lactate dehydrogenase expression, apoptosis, caspase-3/-9 levels and Bax protein expression by regulating the EGFR/PI3K/AKT signaling pathway (36). In the present study, miR-145 overexpression inhibited the PI3K/AKT signaling pathway, which may be the mechanism underlying the effects of miR-145-5p on SCC9 and Cal27 cell invasion, apoptosis and oxidative stress.

There are some limitations to the present study. It remains unknown whether there are differences in the expression of mir-145-5p with regards to tumor size and node metastasis. Moreover, the targeting gene of miR-145-5p is yet to be identified, These questions should be scientifically examined in future studies.

In conclusion, the present study demonstrated that miR-145-5p downregulation affected the progression of cancer. Furthermore, miR-145-5p overexpression increased the antiapoptotic and antioxidative stress effects of SCC9 and Cal27 cells by inhibiting the PI3K/AKT signaling pathway. Therefore, the present study provided a theoretical basis for the use of miR-145 as a molecular marker of TSCC.

\section{Acknowledgements}

Not applicable.

\section{Funding}

This study was funded by the Nature Science Foundation of Liaoning Province (grant no. 2015020326).

\section{Availability of data and materials}

The datasets used and/or analyzed during the current study are available from the corresponding author on reasonable request.

\section{Authors' contributions}

Study design: ZX and CL. Performance of the study: ZX. Data collection: ZT. Data interpretation: JT and ZT. Drafting of the manuscript: ZX and ZT. All authors have read and approved the final submitted manuscript.

\section{Ethics approval and consent to participate}

The present study was approved by the Ethics Committees of Jinzhou Medical University on 26 October, 2016 (approval no. JZH2016052). Informed consent was obtained from all patients included in the study. The research was conducted in accordance with the Helsinki Declaration.

\section{Patient consent for publication}

Not applicable.

\section{Competing interests}

The authors declare that they have no competing interests.

\section{References}

1. Ferlay J, Soerjomataram I, Dikshit R, Eser S, Mathers C, Rebelo M, Parkin DM, Forman D and Bray F: Cancer incidence and mortality worldwide: Sources, methods and major patterns in GLOBOCAN 2012. Int J Cancer 136: E359-E386, 2015.

2. Weatherspoon DJ, Chattopadhyay A, Boroumand S and Garcia I: Oral cavity and oropharyngeal cancer incidence trends and disparities in the United States: 2000-2010. Cancer Epidemiol 39: 497-504, 2015.

3. Rusthoven K, Ballonoff A, Raben D and Chen C: Poor prognosis in patients with stage I and II oral tongue squamous cell carcinoma. Cancer 112: 345-351, 2008.

4. St John MA, Abemayor E and Wong DT: Recent new approaches to the treatment of head and neck cancer. Anticancer Drugs 17: 365-375, 2006.

5. Yan D, Cai X and Feng Y: miR-183 modulates cell apoptosis and proliferation in tongue squamous cell carcinoma SCC25 cell line. Oncol Res 24: 399-404, 2016.

6. Iorio MV, Visone R, Di Leva G, Donati V, Petrocca F, Casalini P, Taccioli C, Volinia S, Liu CG, Alder H, et al: MicroRNA signatures in human ovarian cancer. Cancer Res 67: 8699-8707, 2007.

7. Isayeva T, Brandwein-Gensler $M$, Somarathna $M$, Moore-Smith LD and Lee T: Micro-RNA profiling as a predictor of clinical outcomes for head and neck cancer patients. Curr Pharm Des 23: 4729-4744, 2017.

8. Shi B, Yan W, Liu G and Guo Y: MicroRNA-488 inhibits tongue squamous carcinoma cell invasion and EMT by directly targeting ATF3. Cell Mol Biol Lett 23: 28, 2018.

9. Pardini B, De Maria D, Francavilla A, Di Gaetano C, Ronco G and Naccarati A: MicroRNAs as markers of progression in cervical cancer: A systematic review. BMC Cancer 18: 696, 2018.

10. Arndt GM, Dossey L, Cullen LM, Lai A, Druker R, Eisbacher M, Zhang C, Tran N, Fan H, Retzlaff K, et al: Characterization of global microRNA expression reveals oncogenic potential of miR-145 in metastatic colorectal cancer. BMC Cancer 9: 374 2009.

11. Chiyomaru T, Enokida H, Tatarano S, Kawahara K, Uchida Y, Nishiyama K, Fujimura L, Kikkawa N, Seki N and Nakagawa M: miR-145 and miR-133a function as tumour suppressors and directly regulate FSCN1 expression in bladder cancer. Br J Cancer 102: 883-891, 2010.

12. Zaman MS, Chen Y, Deng G, Shahryari V, Suh SO, Saini S, Majid S, Liu J, Khatri G, Tanaka Y, et al: The functional significance of microRNA-145 in prostate cancer. Br J Cancer 103: 256-264, 2010.

13. Ye D, Shen Z and Zhou S: Function of microRNA-145 and mechanisms underlying its role in malignant tumor diagnosis and treatment. Cancer Manag Res 11: 969-979, 2019.

14. Kano M, Seki N, Kikkawa N, Fujimura L, Hoshino I, Akutsu Y, Chiyomaru T, Enokida H, Nakagawa $\mathrm{M}$ and Matsubara $\mathrm{H}$ : miR-145, miR-133a and miR-133b: Tumor-suppressive miRNAs target FSCN1 in esophageal squamous cell carcinoma. Int J Cancer 127: 2804-2814, 2010.

15. Livak KJ and Schmittgen TD: Analysis of relative gene expression data using real-time quantitative PCR and the 2(-Delta Delta C(T)) Method. Methods 25: 402-408, 2001.

16. Edge SB and Compton CC: The American Joint Committee on Cancer: the 7th edition of the AJCC cancer staging manual and the future of TNM. Ann Surg Oncol 2010;17:1471-1474.

17. Karatas OF, Oner M, Abay A and Diyapoglu A: MicroRNAs in human tongue squamous cell carcinoma: From pathogenesis to therapeutic implications. Oral Oncol 67: 124-130, 2017. 
18. Harding RL and Velleman SG: MicroRNA regulation of myogenic satellite cell proliferation and differentiation. Mol Cell Biochem 412: 181-195, 2016.

19. Zhou X, Yue Y, Wang R, Gong B and Duan Z: MicroRNA-145 inhibits tumorigenesis and invasion of cervical cancer stem cells. Int J Oncol 50: 853-862, 2017.

20. Shen X, Jiang H, Chen Z, Lu B, Zhu Y, Mao J, Chai K and Chen W: MicroRNA-145 inhibits cell migration and invasion in colorectal cancer by targeting TWIST. OncoTargets Ther 12: 10799-10809, 2019.

21. Liu Q, Chen J, Wang B, Zheng Y, Wan Y, Wang Y, Zhou L, Liu S Li G and Yan Y: miR-145 modulates epithelial-mesenchymal transition and invasion by targeting ZEB2 in non-small cell lung cancer cell lines. J Cell Biochem, 2018

22. Xia F, Xiong Y and Li Q: Interaction of lincRNA ROR and p53/ miR-145 correlates with lung cancer stem cell signatures. J Cell Biochem: May 18, 2017. https://doi.org/10.1002/jcb.25960.

23. Wei H, Wen-Ming C and Jun-Bo J: Plasma miR-145 as a novel biomarker for the diagnosis and radiosensitivity prediction of human cervical cancer. J Int Med Res 45: 1054-1060, 2017.

24. Tabrizi M, Khalili M, Vasei M, Nouraei N, Mansour Samaei N, Khavanin A, Khajehei M and Mowla SJ: Evaluating the miR-302b and miR-145 expression in formalin-fixed paraffin-embedded samples of esophageal squamous cell carcinoma. Arch Iran Med 18: 173-178, 2015

25. Sheng N, Tan G, You W, Chen H, Gong J, Chen D, Zhang H and Wang Z: MiR-145 inhibits human colorectal cancer cell migration and invasion via PAK4-dependent pathway. Cancer Med 6: 1331-1340, 2017.

26. Mei LL, Wang WJ, Qiu YT, Xie XF, Bai J and Shi ZZ: miR-145-5p suppresses tumor cell migration, invasion and epithelial to mesenchymal transition by regulating the $\mathrm{Sp} 1 / \mathrm{NF}-\kappa \mathrm{B}$ signaling pathway in esophageal squamous cell carcinoma. Int J Mol Sci 18: 18, 2017.

27. Han Q, Zhang HY, Zhong BL, Wang XJ, Zhang B and Chen H: MicroRNA-145 inhibits cell migration and invasion and regulates epithelial-mesenchymal transition (EMT) by targeting connective tissue growth factor (CTGF) in esophageal squamous cell carcinoma. Med Sci Monit 22: 3925-3934,2016.

28. Calin GA, Sevignani C, Dumitru CD, Hyslop T, Noch E, Yendamuri S, Shimizu M, Rattan S, Bullrich F, Negrini M, et al: Human microRNA genes are frequently located at fragile sites and genomic regions involved in cancers. Proc Natl Acad Sci USA 101: 2999-3004, 2004.
29. Jin C, Wang A, Liu L, Wang G, Li G and Han Z: miR-145-5p inhibits tumor occurrence and metastasis through the NF- $\kappa B$ signaling pathway by targeting TLR4 in malignant melanoma. J Cell Biochem 120: 11115-11126, 2019.

30. Kliese N, Gobrecht P, Pachow D, Andrae N, Wilisch-Neumann A, Kirches E, Riek-Burchardt M, Angenstein F, Reifenberger G, Riemenschneider MJ, et al: miRNA-145 is downregulated in atypical and anaplastic meningiomas and negatively regulates motility and proliferation of meningioma cells. Oncogene 32: 4712-4720, 2013

31. Yang C, Xia Z, Zhu L, Li Y, Zheng Z, Liang J and Wu L: MicroRNA-139-5p modulates the growth and metastasis of malignant melanoma cells via the PI3K/AKT signaling pathway by binding to IGF1R. Cell Cycle 18: 3513-3524, 2019.

32. Shi X, Wang J, Lei Y, Cong C, Tan D and Zhou X: Research progress on the PI3K/AKT signaling pathway in gynecological cancer (Review). Mol Med Rep 19: 4529-4535, 2019.

33. Zhu X and Zhu R: Curcumin suppresses the progression of laryngeal squamous cell carcinoma through the upregulation of miR-145 and inhibition of the PI3K/Akt/mTOR pathway. OncoTargets Ther 11: 3521-3531, 2018.

34. Liu S, Gao G, Yan D, Chen X, Yao X, Guo S, Li G and Zhao Y: Effects of miR-145-5p through NRAS on the cell proliferation, apoptosis, migration, and invasion in melanoma by inhibiting MAPK and PI3K/AKT pathways. Cancer Med 6: 819-833, 2017.

35. Li B, Ding CM, Li YX, Peng JC, Geng N and Qin WW: MicroRNA-145 inhibits migration and induces apoptosis in human non-small cell lung cancer cells through regulation of the EGFR/PI3K/AKT signaling pathway. Oncol Rep 40: 2944-2954 2018.

36. Cheng Z, Dai LL, Wang X, Jia LQ, Jing XG, Li PF, Liu M, Wang $\mathrm{H}$ and An L: MicroRNA-145 down-regulates mucin 5AC to alleviate airway remodeling and targets EGFR to inhibit cytokine expression. Oncotarget 8: 46312-46325, 2017.

This work is licensed under a Creative Commons Attribution-NonCommercial-NoDerivatives 4.0 International (CC BY-NC-ND 4.0) License. 